\title{
Succinylcholine: The Dilemma with the Evidence
}

\author{
Comment on: Tejirian T, Lewis CE, Conner $\mathbf{J}$ et al. Succinylcholine: \\ A Drug to Avoid in Bariatric Surgery. Obes Surg 2009; 19: 534-6
}

\author{
Jan-Uwe Schreiber • Thomas Fuchs-Buder
}

Received: 6 July 2009 /Accepted: 24 September 2009 /Published online: 14 October 2009

(C) The Author(s) 2009. This article is published with open access at Springerlink.com

To the editor:

We have read with interest the case report by Terijian and colleagues and the comment from Brodsky et al. [1,2].

We fully agree with the authors that succinylcholineassociated myalgia might be a serious issue for many patients, especially for morbidly obese patients. But we were a little bit surprised about the authors' opinion that there are no proven strategies to reduce succinylcholine-associated myalgia significantly. The authors have cited a meta-analysis by Schreiber et al. that was published in 2005 in Anesthesiology [3]. In this article it has been shown that the relative risk of postoperative myalgia can be reduced significantly by using a pretreatment with low-dose non-depolarizing neuromuscular blockers or sodium channel blockers such as lidocaine. Currently, the paper represents the best available evidence on the prevention of succinylcholine-associated myalgia.

Furthermore, we agree that sugammadex, a new binding agent for the reversal of rocuronium and vecuronium, will improve the safety profile of these agents but we are not convinced that this will be the solution of all of our problems. In case of a rapid sequence induction, the anesthesiologist wants optimal intubation conditions within seconds and in this specific situation succinylcholine still seems to be superior compared to high-dose rocuroniumaccording to a recent systematic review that was very well done by Perry et al. [4].

The dilemma of systematic reviews and meta-analyses might be that they cannot focus onto specific patient populations. This could be seen as a limitation of evidence-based approaches. On the other hand, it represents the best wayunless the contrary has been proven.

Another aspect emerges from this case report. After dramatic improvements in clinical anesthesia during the last 50 years, a "dirty drug" that may cause potentially fatal complications such as malignant hyperthermia or hyperkalemia still represents the "gold standard" for rapid sequence induction. Surely, a non-depolarizing agent with a comparable pharmacological profile but no side effects would be the best replacement. Unfortunately, it has not been found yet.

Open Access This article is distributed under the terms of the Creative Commons Attribution Noncommercial License which permits any noncommercial use, distribution, and reproduction in any medium, provided the original author(s) and source are credited.

\footnotetext{
J.-U. Schreiber $(\bowtie)$

Department of Anesthesia and Pain Therapy,

Maastricht University Medical Center,

P. Debyelaan 25,

6229 HX Maastricht, The Netherlands

e-mail: j.schreiber@mumc.nl

T. Fuchs-Buder

Department of Anesthesia and Critical Care,

Centre Hospitalier Universitaire Brabois,

Nancy, France
}

\section{References}

1. Tejirian T, Lewis CE, Conner J, et al. Succinylcholine: a drug to avoid in bariatric surgery. Obes Surg. 2009;19:534-6.

2. Brodsky JB, Lemmens HJM, Morton JM. Succinylcholine: a drug useful in bariatric surgery. Obes Surg. 2009;19:537.

3. Schreiber JU, Lysakowski C, Fuchs-Buder T, et al. Prevention of succinylcholine-induced fasciculation and myalgia: a meta-analysis of randomized trials. Anesthesiology. 2005;103:877-84.

4. Perry JJ, Lee JS, Sillberg VA, et al. Rocuronium versus succinylcholine for rapid sequence induction intubation. Cochrane Database Syst Rev. 2008;2:CD002788. 